\title{
Early onset muscarinic manifestations after wild mushroom ingestion
}

\author{
Keng Sheng Chew • Mohd Amin Mohidin • \\ Mohd Zikri Ahmad • \\ Tuan Hairul Nizam Tuan Kamauzaman • \\ Nasir Mohamad
}

Received: 18 April 2008 / Accepted: 21 July 2008 / Published online: 4 September 2008

(C) Springer-Verlag London Ltd 2008

\begin{abstract}
Despite being a favorite delicacy, only 200-300 of the 5,000 known mushroom species have been clearly established to be safe for consumption. Cases of mushroom poisoning have been reported with diverse clinical syndromes. A syndromic classification of mushroom poisoning has recently been developed to facilitate early interventions. We present a series of five cases of mushroom poisoning with muscarinic manifestations to highlight the difficulties we faced with exact species and toxin identification and the importance of this syndromic classification. The common symptoms in our case series are blurred vision, diarrhea, vomiting, and abdominal cramps.
\end{abstract}

Keywords Mushroom poisoning $\cdot$ Muscarinic $\cdot$ Syndromic classification · Atropine

\section{Introduction}

Mushrooms are a favorite delicacy in many parts of the world, including Malaysia. One of the dominant varieties cultivated in this part of Southeast Asia is the grey oyster mushroom (Pleurotus ostreatus) [1]. There are an increasing number of toxicology reports [2,3] resulting from uncultivated mushroom consumption. Many of these uncultivated mushroom varieties are the wild types, ingested because of their physical resemblance to the known edible varieties [2], while others are ingesting these

K. S. Chew $(\triangle) \cdot$ M. A. Mohidin $\cdot$ M. Z. Ahmad

T. H. N. Tuan Kamauzaman • N. Mohamad

Emergency Medicine Department, School of Medical Sciences,

Universiti Sains Malaysia,

16150 Kubang Kerian, Kelantan, Malaysia

e-mail: cksheng74@yahoo.com foraged varieties for their psychedelic effects [4]. Although there are as many as 5,000 mushroom species, only 200 300 varieties have clearly been established to be safe for consumption, whereas approximately 50-100 types are known to be poisonous [2]. For the majority of the other mushroom species, whether they are edible or poisonous has not been established [2]. In this article, we report a series of five cases of mushroom poisoning that occurred in a family.

\section{Case reports}

\section{Patient A}

Patient A, a 24-year-old farmer, found wild mushrooms growing in his orchard and plucked them for consumption, thinking that they appeared similar to some he had eaten before.

Two hours after consuming the mushrooms, he started to develop blurred vision, giddiness, and vomited twice prior to his admission to the emergency department (ED) of the Hospital Universiti Sains Malaysia.

When he arrived, he was diaphoretic, with drenching sweats, copious salivation and lacrimation, as well as crampy abdominal pain (Fig. 1). He vomited twice in the ED and had one episode of loose stools. Otherwise, his vital signs were stable. His pupils were measured at $3 \mathrm{~mm}$ bilaterally and were reactive to light. On auscultation of the lungs, there were coarse crackles up to the mid lung bilaterally. With his muscarinic syndromic presentation, intravenous atropine infusion and activated charcoal were administered.

He was admitted to the general medical ward. Within a few hours, his secretions and his general condition 


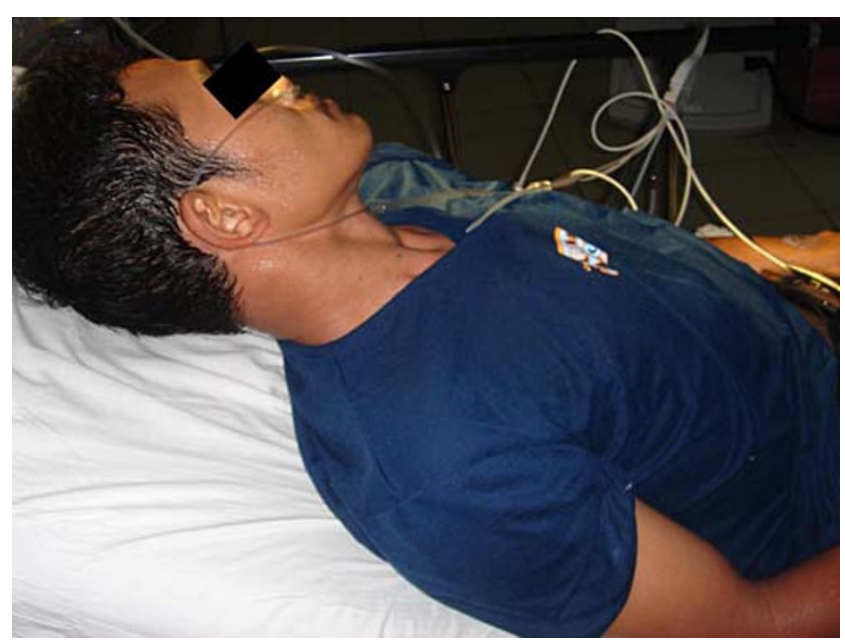

Fig. 1 Shows the condition of patient A with drenching sweat

improved. His liver transaminases tests were within normal range [aspartate aminotransferase (AST) $31 \mathrm{U} / 1$, alanine aminotransferas (ALT) $15 \mathrm{U} / \mathrm{l}$, and alkaline phosphatase (ALP) $36 \mathrm{U} / 1$ ]. He was discharged after 2 days in the wards.

\section{Patient B}

Patient B, a 32-year-old Malay female, was the spouse of patient A. Like her husband, she started having episodes of crampy abdominal pain with loose stools and vomiting as well as blurred vision $2 \mathrm{~h}$ after consuming the mushrooms. She also had profuse sweating, lacrimation, and lung crepitus. Like her husband, she was also given intravenous atropine infusion besides activated charcoal. She was admitted to the general medical ward and discharged at about the same time as her husband. Her transaminases remained normal.

\section{Patient C}

Patient $\mathrm{C}$ was a 32-year-old Malay female, the elder sister of patient A. She cooked the sliced mushrooms gathered by her brother by sautéing them. She developed blurred vision with three episodes of diarrhea and vomiting. She had mild sweating but no increase in lacrimation. Her lungs were clear on auscultation. She was given activated charcoal, but not intravenous atropine. She was monitored in the observation ward in the ED and was discharged after $6 \mathrm{~h}$ of observation.

\section{Patient D}

Patient $\mathrm{D}$ was the younger sister of patient $\mathrm{C}$. Like her elder sister, this 13-year-old Malay female also presented with two episodes of vomiting and diarrhea as well as mild sweating. She was given activated charcoal, but not
Table 1 Symptom presentation of the five patients

\begin{tabular}{llllll}
\hline & $\begin{array}{l}\text { Patient } \\
\text { A }\end{array}$ & $\begin{array}{l}\text { Patient } \\
\text { B }\end{array}$ & $\begin{array}{l}\text { Patient } \\
\text { C }\end{array}$ & $\begin{array}{l}\text { Patient } \\
\text { D }\end{array}$ & $\begin{array}{l}\text { Patient } \\
\text { E }\end{array}$ \\
\hline Blurred vision & $\mathrm{X}$ & $\mathrm{X}$ & $\mathrm{X}$ & $\mathrm{X}$ & $\mathrm{X}$ \\
Diarrhea & $\mathrm{X}$ & $\mathrm{X}$ & $\mathrm{X}$ & $\mathrm{X}$ & - \\
Vomiting & $\mathrm{X}$ & $\mathrm{X}$ & $\mathrm{X}$ & $\mathrm{X}$ & - \\
Abdominal cramps & $\mathrm{X}$ & $\mathrm{X}$ & $\mathrm{X}$ & $\mathrm{X}$ & - \\
Lacrimation & $\mathrm{X}$ & $\mathrm{X}$ & - & - & - \\
Salivation & $\mathrm{X}$ & - & - & - & - \\
\hline
\end{tabular}

intravenous atropine. She was discharged symptom-free after $6 \mathrm{~h}$ of observation in the ED.

\section{Patient E}

Patient E was the father of patients A, C, and D. He had blurred vision. Other than that, he had no other symptoms. He was monitored in the observation ward in the emergency department, then was well and discharged home.

A summary of the symptom presentation of all five patients is given in Table 1.

One of the family members brought some left-over sliced raw mushroom pieces to us (see Fig. 2). We sent them for identification to the National Poison Center in Penang, Malaysia. Unfortunately, the National Poison Center can only test for a limited number of toxin assays using gas chromatography with mass spectrometry. The toxins tested were muscimol, bufotenine, psilocybin, and gyromitrin - all of which tested negative in our sample. We attempted to take a second sample from the family's house; however, no more similar mushrooms grew in the vicinity. Furthermore, the sample provided to us was sliced pieces of raw mushroom wrapped in a clear plastic bag. This could

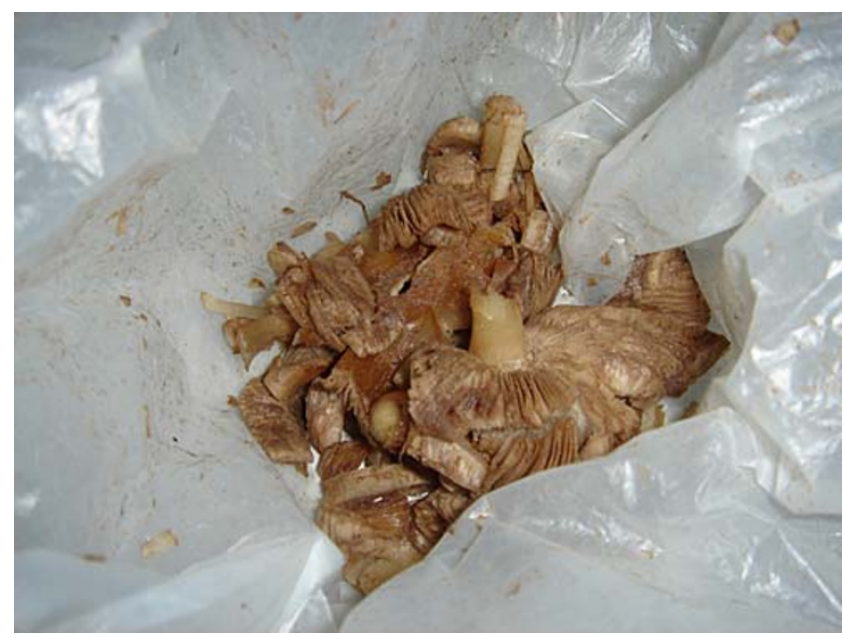

Fig. 2 The mushroom samples given by the family 
lead to a potential source of error because the recommended method of sampling should be to dig up the entire mushroom in order to preserve the bulb-stem-cap architecture and to transport them in a dry paper bag in their entirety without crushing or refrigerating them [4]. This reduces the risk of autolysis of the sample and prevents discoloration and premature release of spores [4].

One week after patients A and B were discharged from the ward, we conducted a follow-up telephone interview to check their general conditions. All of them were well without any residual symptoms.

\section{Discussion}

These cases illustrate the difficulties of exact species and toxin identification and the importance of the recent introduction of syndromic classification for mushroom poisoning.

In 1987, Zilker suggested that the diagnosis of mushroom poisoning should be based on three principles: the description of the mushroom, the toxicological analysis of the mushroom, and, most importantly, the presenting syndrome [5]. Later on, Blackman, in his review article, suggested mushroom poisoning can be stratified into seven clinical profiles [6]. He further recommended a cut-off point of $6 \mathrm{~h}$ in terms of the duration of symptom onset after ingestion rather than $4 \mathrm{~h}$ as suggested by Zilker [5]. This is because patients who present with symptom onset of more than $6 \mathrm{~h}$ suggest a more serious poisoning due to species that contain gyromitrin and amanitin as compared to those that present with a delay of less than $6 \mathrm{~h}$. Many other classification systems for mushroom poisoning have been developed over the years [7-9]. However, as shown by the American Association of Poison Control Center's (AAPCC) data, problems remain because the exact species and toxins go unidentified in more than $95 \%$ and $90 \%$ of the cases, respectively [4]. This further attests to the difficulties in the management of mushroom poisoning.

Because of these factors, a recent syndromic classification of mushroom poisoning has been developed to facilitate direct, earlier diagnosis and permit prompt interventions with specific therapies [4].

Under this syndromic classification, any mushroom poisoning case is first stratified into three different presentation timings - early onset (less than $6 \mathrm{~h}$ ), late onset (6-24 h), and delayed onset (more than 1 day). Under each presentation timing category, the case is then further stratified into different predominant organ toxicities. There are eight early onset syndromes (four neurotoxic, two gastrointestinal, and two allergic), three late onset syndromes (hepatotoxic, accelerated nephrotoxic, and erythromelalgia), and finally, three delayed onset syndromes (delayed nephrotoxic, delayed neurotoxic, and rhabdomyolysis). The four neurotoxic early onset syndromes are cholinergic (the category where the cases presented here are stratified), glutaminergic, epileptogenic, and hallucinogenic [4, 10].

Many of the case reports that have been published before concern late-onset hepatotoxic manifestations due to Amanita [3, 4] species mushroom poisoning [11, 12]. This is because the most severe forms of poisoning and fatalities are usually due to ingestion of mushrooms from this group $[3,4]$, except for sporadically reported cases due to other mushroom groups [13].

In this paper, we highlight five cases of mushroom poisoning that presented not with hepatotoxic manifestations, but with muscarinic symptoms. These symptoms usually occur due to mushroom ingestions of the Inocybe or Clitocybe species group [14-16]. In our cases, even though not identified due to the lack of a second sample, this did not deter us from early implementation of specific therapies based on the recognition of common signs and symptoms.

Mushroom poisoning with muscarinic toxidrome can present with a variety of signs and symptoms that can even vary among persons who ingested the mushroom grown in the same patch at the same time. This is clearly illustrated in the five cases presented in this paper. Therefore, accurate diagnosis of poisoning due to muscarine-containing mushrooms should not depend on the recognition of the species, but rather on the recognition of the common muscarinic manifestations, particularly the diaphoresis, salivation, bladder cramping, diarrhea, and difficulty with visual accommodation $[10,16]$. These typical symptoms were all seen in all of our patients, especially in patients A and B, although the most common symptom in our cases was the transient blurring of vision.

Nevertheless, unlike poisoning due to the Amanita species, which usually manifests after $6 \mathrm{~h}$, fatalities are rare with early onset muscarine-containing mushrooms [4, 10]. In 2007, Pauli and Foot described the first ever reported fatality in Australia due to the ingestion of wild mushrooms with muscarinic syndrome [13]. In their case, it was a 53-year-old woman who died $10 \mathrm{~h}$ post ingestion of Rubinoboletus sp., which had not been reported to result in death in the English language literature before [13]. This again testifies to the rarity of fatality secondary to ingestion of muscarine-containing mushrooms.

Treatment of muscarine-containing mushroom poisoning is mainly supportive, consisting primarily of administration of activated charcoal [3,10,17, 18]. Activated charcoal is an effective, inert, and nontoxic adsorbant that irreversibly binds intraluminal toxins and interferes with their absorption, especially for high molecular weight compounds [17, 18]. To control secretions [10], intravenous atropine is the treatment of choice $[3,10,16]$. Other than that, no other 
specific antidotes are available for muscarinic toxidrome mushroom poisoning [10]. In fact, there is no commonly available analytical technique to identifiy muscarine in body fluids [10].

\section{Conclusion}

In conclusion, we believe one should not be too preoccupied with the exact identification of species and toxins before initiating treatment for mushroom poisoning, which only leads to a delay in treatment. The number of species and toxins are too numerous, and in many countries like Malaysia, the number of species and toxins that can be identified is limited. In this regards, we find that the syndromic classification of mushroom poisonings is very useful to facilitate treatment and stratification of cases. Secondly, as the identification of the different toxidromes in poisoning can be a very difficult task even for the most astute and experienced physicians, one should always maintain a high level of suspicion when handling such cases [17, 18]. Perhaps the use of a preformatted, standardized admission chart designed specifically for poisoning admission would help facilitate clinical assessment, as well as serve as a database for comprehensive research undertakings in the area of toxicology [19].

\section{References}

1. Oyster Mushroom. In: Wikipedia. Available at http://en.wikipedia. org/wiki/Oyster_mushroom. Accessed 15 March 2008

2. Berger KJ, Guss DA (2005) Mycotoxins revisited: part I. J Emerg Med 28(1):53-62
3. Erguven M, Yilmaz O, Deveci M, Aksu N, Dursun F, Pelit M, Cebeci N (2007) Mushroom poisoning. Indian J Pediatr 74 (9):847-852, Sep

4. Diaz JH (2005) Evolving global epidemiology, syndromic classification, general management, and prevention of unknown mushroom poisonings. Crit Care Med 33(2):419-426

5. Zilker T (1987) Diagnosis and therapy of mushroom poisoning (1). Leber Magen Darm 17(2):97-112

6. Blackman JR (1994) Clinical approach to toxic mushroom ingestion. J Am Board Fam Pract 7(1):31-37

7. Kohn R, Mot'ovska Z (1997) Mushroom poisoning-classification, symptoms and therapy. Vnitr Lek 43(4):230-233

8. Karlson-Stiber C, Persson H (2003) Cytotoxic fungi-an overview. Toxicon 42(4):339-349

9. Saviuc P, Flesch F (2003) Acute higher funghi mushroom poisoning and its treatment. Presse Med 32(30):1427-1435

10. Diaz JH (2005) Syndromic diagnosis and management of confirmed mushroom poisonings. Crit Care Med 33(2):427-436

11. Alves A, Gouveia Ferreira M, Paulo J et al (2001) Mushroom poisoning with Amanita phalloides - a report of four cases. Eur J Intern Med 12(1):64-66

12. From the Centers for Disease Control and Prevention (1997) Amanita phalloides mushroom poisoning-northern California, January 1997. JAMA 278(1):16-17

13. Pauli JL, Foot CL (2005) Fatal muscarinic syndrome after eating wild mushrooms. Med J Aust 182(6):294-295, Mar 21

14. Genest K, Hughes DW, Rice WB (1968) Muscarine in Clitocybe species. J Pharm Sci 57(2):331-333

15. Berger KJ, Guss DA (2005) Mycotoxins revisited: part II. J Emerg Med 28(2):175-183

16. Stallard D, Edes TE (1989) Muscarinic poisoning from medications and mushrooms. A puzzling symptom complex. Postgrad Med 85(1):341-345

17. Mokhlesi B, Corbridge T (2003) Toxicology in the critically ill patient. Clin Chest Med 24(4):689-711, Dec

18. Mokhlesi B, Leiken JB, Murray P, Corbridge TC (2003) Adult toxicology in critical care: part I: general approach to the intoxicated patient. Chest 123(2):577-592, Feb

19. Buckley NA, Whyte IM, Dawson AH, Reith DA (1999) Preformatted admission charts for poisoning admissions facilitate clinical assessment and research. Ann Emerg Med 34(4 Pt 1): 476-482, Oct 